\title{
Modelo para alinhamento entre a maturidade dos sistemas de medição de desempenho e a maturidade da gestão da cadeia de suprimentos
}

\author{
Model for alignment between performance measurement systems \\ and maturity of supply chain management
}

\author{
Guilherme Francisco Frederico' \\ Roberto Antonio Martins ${ }^{1}$
}

\begin{abstract}
Resumo: As cadeias de suprimentos são cada vez mais importantes para a sobrevivência das empresas no mercado competitivo atual. Teorias e métodos que contribuam para a melhoria de sua gestão são elementos importantes para a pesquisa e o desenvolvimento na área da Engenharia de Produção. Considerando os sistemas de medição de desempenho como um desses elementos, este artigo tem por objetivo apresentar um modelo para alinhamento entre sistemas de medição de desempenho e sua maturidade aos níveis de maturidade da gestão da cadeia de suprimentos. Para isso, foram estudados os sistemas de medição de desempenho e sua maturidade, bem como os modelos de maturidade para a gestão da cadeia de suprimentos, permitindo, desta forma, a construção de um modelo teórico de relação entre estes dois elementos. Com o uso do método de pesquisa de estudo de múltiplos casos aplicados em três diferentes unidades de análise, foi possível verificar a aderência do modelo teórico proposto. Como principais resultados, na maioria dos casos, foi identificada a existência de uma relação entre a maturidade do sistema de medição de desempenho e a maturidade da gestão da cadeia de suprimentos, embora nem sempre todas as dimensões da maturidade dos dois elementos encontrem-se em um mesmo nível de desenvolvimento. Como contribuição, o modelo busca apresentar uma abordagem inédita para a teoria dos sistemas de medição de desempenho no âmbito da gestão da cadeia de suprimentos, como também, proporcionar aos praticantes o alinhamento correto entre a maturidade da gestão da cadeia de suprimentos e a maturidade dos sistemas de medição de desempenho.
\end{abstract}

Palavras-chave: Sistemas de medição de desempenho. Gestão da cadeia de suprimentos. Maturidade dos sistemas de medição de desempenho. Maturidade da gestão da cadeia de suprimentos.

\begin{abstract}
Supply chains have become increasingly important for companies to survive in today's competitive market. Theories and methods that contribute to the improvement of their management are important elements of research and development in the field of Industrial Engineering. Considering performance measurement systems as one of these elements, this paper aims to propose a model for alignment between performance measurement systems and its maturity to the maturity levels of supply chain management due to the lack of studies that address the relationship between these two elements. Therefore, performance measurement systems and their maturity, as well as maturity models for supply chain management were studied enabling the creation of a theoretical model of relationship between these two elements. The multiple case study method was applied to three different units of analysis to verify the suitability of the theoretical model proposed. In most of the cases, as the main results of this study, it was identified the existence of a relationship between the maturity of performance measurement system and the maturity of supply chain management although the dimensions of maturity of these two elements are not always at the same development level. The contribution of this model is to present a new approach to the theory of the performance measurement systems in the supply chain management, as well as to provide practitioners with the correct alignment between the maturity of supply chain management and maturity of performance measurement systems.
\end{abstract}

Keywords: Performance measurement systems. Supply chain management. Maturity of performance measurement systems. Maturity of supply chain management.

\footnotetext{
${ }^{1}$ Departamento de Engenharia de Produção, Universidade Federal de São Carlos - UFSCar, São Carlos, SP, Brasil,

e-mail: fredericogf@bol.com.br
} 


\section{Introdução}

A competição no mercado não tem ocorrido mais somente entre as empresas, mas também entre as cadeias de suprimentos que competem entre si (CHRISTOPHER, 2005; LAMBERT; COOPER, 2000; PIRES, 2009). O foco da gestão da cadeia de suprimentos deve ser a cooperação e a confiança, sendo que a busca pelo desempenho do todo pode ser melhor que a soma das partes que a constitui (CHRISTOPHER, 2005).

Devido às oportunidades existentes pelas possibilidades de sinergias entre as entidades de cadeias de suprimentos, torna-se necessário, neste cenário de competição entre elas, o desenvolvimento de teorias, métodos e instrumentos que colaborem para o exercício de suas práticas de gestão, pois, gerenciar uma cadeia de suprimentos é uma tarefa difícil e desafiadora, principalmente devido à sua complexidade gerada pela rede de múltiplos membros que a compõe (LAMBERT; COOPER, 2000; CHRISTOPHER, 2005; CHAN et al., 2003; SIMCHI-LEVI; KAMINSKY; SIMCHI-LEVI, 2003; AYERS; MALMBERG, 2002).

Neste contexto, os sistemas de medição de desempenho (SMDs) se destacam como elemento de apoio na gestão da cadeia de suprimentos das organizações, provendo informações para o suporte à tomada de decisão (MORGAN, 2004). Embora o trabalho de propor métricas para cadeias de suprimentos seja uma tarefa difícil, devido à própria complexidade associada a esta área, a partir da década de 1990 iniciou-se a proposição de algumas abordagens relacionadas à medição de desempenho em cadeias de suprimentos, (LAMBERT; POHLEN, 2001). Entre os anos de 1993 e 2000, de acordo com a análise dos artigos publicados em periódicos nacionais e internacionais, apenas $8,6 \%$ do total das publicações estavam relacionados a SMDs para cadeia de suprimentos (TEZZA; BORNIA; VEY, 2010). Este tema tem sido explorado até os dias atuais, devido a sua importância dentro do contexto da gestão da cadeia de suprimentos.

A base conceitual para os sistemas de medição de desempenho está muito desenvolvida para o aspecto "empresa" enfatizando uma unidade de negócio isolada. Contudo, existe uma necessidade de revisão e adequação desse conhecimento já construído para a área de gestão da cadeia de suprimentos (PIRES, 2009).

Os SMDs são um desafio e fator crítico na evolução da gestão da cadeia de suprimentos, sendo necessários estudos sobre essa temática (MORGAN, 2004). Por outro lado, a própria evolução da gestão da cadeia de suprimentos pode exigir uma evolução dos sistemas de medição de desempenho (MARTINS et al., 2008). Um fato constatado, por exemplo, é que a adoção de programas para a obtenção de prêmios de qualidade levou a uma evolução dos SMDs das empresas que aderiram a estes programas (OLIVEIRA; MARTINS, 2008).
Além disso, diversos autores tratam da maturidade da gestão da cadeia de suprimentos. Apesar de não haver uma concordância completa entre esses autores, existem características comuns propostas por eles. Geralmente, a maturidade aumenta com a evolução das práticas implantadas e das tecnologias utilizadas para gerir uma cadeia de suprimentos (STEVENS, 1989; LOCKAMY III; McCORMACK, 2004; OLIVEIRA, 2009; AYERS; MALMBERG, 2002; DAOZHI et al., 2006).

De forma análoga, outros autores também tratam da maturidade dos sistemas de medição de desempenho. Também não há concordância entre as propostas. Contudo, pode-se identificar elementos dos SMDs que se modificam conforme a maturidade aumenta (WETTSTEIN; KUENG, 2002; VAN AKEN et al., 2005).

Todavia, na pesquisa bibliográfica realizada, não foi identificada nenhuma pesquisa que tratasse conjuntamente dos níveis de maturidade da gestão da cadeia de suprimentos e dos sistemas de medição de desempenho. Uma vez que esses dois elementos se relacionam mutualmente, o entendimento desta relação de maturidade entre eles pode ser uma contribuição tanto para a teoria quanto para a prática. Por exemplo, a utilização de um SMD com nível de maturidade avançado para uma gestão da cadeia de suprimentos ainda em estágio inicial de maturidade poderia gerar um esforço desnecessário e um desalinhamento com os propósitos desejados. Por outro lado, a utilização de um SMD com nível de maturidade inicial para uma gestão da cadeia de suprimentos avançada em termos de maturidade não proporcionaria uma medição de desempenho adequada, não provendo a informação necessária aos tomadores de decisão.

Por fim, ainda existe um amplo espaço para pesquisas relacionadas à gestão da cadeia de suprimentos, principalmente por que existem muitas relações entre variáveis que estão relacionadas à gestão da cadeia de suprimentos, as quais ainda não foram exploradas e explicadas, sendo necessária, então, a proposição de novos modelos teóricos para o aprimoramento do conhecimento até então desenvolvido (TEIXEIRA; LACERDA, 2010).

\section{Fundamentação teórica}

Nesta seção, serão apresentados os principais resultados da revisão bibliográfica realizada. Primeiramente serão apresentados os conceitos e os modelos sobre maturidade da gestão da cadeia de suprimentos. Da mesma forma, posteriormente, serão tratados os sistemas de medição de desempenho, com a apresentação dos seus conceitos, dos SMDs para a gestão da cadeia de suprimentos e, por final, da maturidade dos sistemas de medição de desempenho. 


\subsection{Maturidade da gestão da cadeia de suprimentos}

A maturidade é um tema bastante explorado nos últimos anos por parte de pesquisadores na área de gestão de empresas, com foco em diversas áreas. Em relação aos processos organizacionais, Hammer (2007) propõe um modelo de maturidade baseado em dois elementos: facilitadores dos processos e competências organizacionais. Harter, Krishnan e Slaughter (2000) propõem, com base no Capability Maturity Model-CMM, um modelo para o desenvolvimento do software. Kwak e Ibbs (2002) apresentam um modelo para gestão de projetos. Attadia e Martins (2003) propõem um estudo adequando sistemas de medição de desempenho aos estágios de evolução do processo de melhoria contínua, usando como base o modelo desenvolvido por Bessant et al. (2001).

Venkatraman e Henderson (1998) propõem um modelo de maturidade que busca demonstrar os estágios para que uma organização alcance um nível de organização e integração virtual em três dimensões: interação com os clientes (encontro virtual), configuração de ativos (busca para integração virtual) e (alavancar o conhecimento) excelência virtual.

Especificamente para a área de gestão da cadeia de suprimentos, seis modelos foram encontrados na literatura pesquisada, conforme apresenta o
Quadro 1. Destaca-se entre eles o modelo proposto por Lockamy III e McCormack (2004), que utiliza como base o modelo de maturidade do Business Process Orientation (BPO) e que foi desenvolvido a partir dos conceitos de maturidade de processo, CMM e do modelo SCOR.

De acordo com os dados do Quadro 1, o modelo de Lockamy III e McCormack (2004) é o que possui o maior número de dimensões consideradas. Embora ocorra este fato, pode-se observar também que algumas dimensões não consideradas por Lockamy III e McCormack (2004) são consideradas por outros autores. Destacam-se entre elas: gestão de projetos, gestão de riscos, regulamentações e incentivos na cadeia, responsividade e recursos da cadeia.

\subsection{Maturidade dos sistemas de medição de desempenho}

A medição de desempenho é definida como o processo de quantificação da eficiência e da eficácia de uma ação. A medida de desempenho pode ser definida como a métrica utilizada para quantificar a eficiência e a eficácia de uma ação. Já o sistema de medição de desempenho é definido como o conjunto de métricas usadas para quantificar a eficiência e a eficácia das ações (NEELY; GREGORY; PLATTS, 1995). Um sistema de medição de desempenho permite que decisões e ações sejam efetivadas com base em

Quadro 1. Modelos de maturidade para a gestão da cadeia de suprimentos.

\begin{tabular}{|c|c|}
\hline Autores & Dimensões Consideradas \\
\hline Stevens (1989) & $\begin{array}{l}\text { Nível de estoques, fronteira organizacional, foco no cliente, custos na cadeia de } \\
\text { suprimentos, planejamento, visibilidade e orientação pela demanda, foco estratégico, } \\
\text { parceria e colaboração na cadeia, responsividade, tecnologia da informação e } \\
\text { sistemas de controle e compartilhamento de informações. }\end{array}$ \\
\hline Ayers e Malmberg (2002) & $\begin{array}{l}\text { Custos na cadeia de suprimentos, planejamento, foco estratégico, parceria e } \\
\text { colaboração na cadeia, filosofia em gestão da cadeia de suprimentos, gestão de } \\
\text { projetos, formalização e estruturação de processos, integração de processos, tecnologia } \\
\text { da informação e sistemas de controle e compartilhamento de informações e ganhos. }\end{array}$ \\
\hline $\begin{array}{l}\text { Lockamy III e McCormack } \\
\qquad(2004)\end{array}$ & $\begin{array}{l}\text { Fronteira organizacional, foco no cliente, satisfação do cliente, custos na cadeia de } \\
\text { suprimentos, planejamento, foco estratégico, parceria e colaboração, formalização } \\
\text { e estruturação de processos, integração de processos, tecnologia da informação e } \\
\text { sistemas de controle, compartilhamento de informações e de ganhos, medição de } \\
\text { desempenho e competitividade da cadeia. }\end{array}$ \\
\hline Daozhi et al. (2006) & $\begin{array}{l}\text { Custos na cadeia de suprimentos, parceria e colaboração, responsividade, gestão } \\
\text { de riscos, compartilhamento de informações, compartilhamento de recursos, } \\
\text { regulamentação e incentivos na cadeia e recursos utilizados na cadeia. }\end{array}$ \\
\hline $\begin{array}{l}\text { Performance Measurement } \\
\text { Group (2007) }\end{array}$ & $\begin{array}{l}\text { Fronteira organizacional, planejamento, foco estratégico, parceria e colaboração } \\
\text { na cadeia, responsividade, formalização e estruturação de processos, integração de } \\
\text { processos, tecnologia da informação e sistemas de controle e medição de desempenho. }\end{array}$ \\
\hline Oliveira (2009) & $\begin{array}{l}\text { Foco no cliente, satisfação do cliente, planejamento, visibilidade e orientação } \\
\text { pela demanda, foco estratégico, parceria e colaboração na cadeia, responsividade, } \\
\text { formalização e estruturação de processos, integração de processos, tecnologia da } \\
\text { informação e sistemas de controle, compartilhamento de informações e medição de } \\
\text { desempenho. }\end{array}$ \\
\hline
\end{tabular}


informações relacionadas a decisões passadas, com a aquisição, compilação, arranjo, análise, interpretação e disseminação de dados adequados (NEELY, 1998).

Os sistemas de medição de desempenho devem possuir uma característica dinâmica em relação às mudanças que possam ocorrer no ambiente no qual estão inseridos (BITITCI; TURNER; BEGEMANN, 2000; KENNERLEY; NELLY, 2003). Por este motivo, entender a evolução da maturidade de um sistema de medição de desempenho é muito importante, pois é necessário que tal sistema seja capaz de mudar de acordo com as mudanças ocorridas no ambiente, buscando-se desta forma, ser aderente às novas demandas de informação sobre o desempenho.

O Quadro 2 apresenta os sistemas de medição de desempenho para a gestão da cadeia de suprimentos presentes na literatura.

De acordo com os dados do Quadro 2, os sistemas de medição de desempenho propostos por Holmberg (2000) e Chan et al. (2003) são mais ligados à estrutura de um sistema de medição de desempenho, tendo em vista que eles tratam mais sobre a extensão do sistema ao longo da cadeia e também da presença do SMD nas principais áreas da cadeia de suprimentos do que das próprias medidas de desempenho a serem utilizadas. Por outro lado, os outros sistemas tratam quase que unicamente das medidas de desempenho para dar suporte à gestão da cadeia de suprimentos.
Outro ponto a ser salientado é que os sistemas de medição de desempenho propostos após os anos de 2000 são mais abrangentes em termos de perspectivas de medição, considerando outros aspectos, além de clientes, processos e desempenho financeiro.

Em relação à maturidade do sistema de medição de desempenho do negócio, dois modelos foram encontrados na literatura pesquisada. $\mathrm{O}$ primeiro modelo foi proposto por Wettstein e Kueng (2002). Construído com base no conceito do CMM, tal modelo tem cinco dimensões: escopo de medição, coleta de dados, armazenagem de dados, comunicação dos resultados, uso dos indicadores de desempenho e qualidade do processo de medição. Já, o segundo modelo, proposto por Van Aken et al. (2005) é baseado no Improvement System Assessment Tool (ISAT). Tal modelo foca mais na avaliação do sistema de medição de desempenho considerando seu processo de melhoria e não dimensões de maturidade propriamente ditas. O modelo também prevê a avaliação dos resultados alcançados por meio do uso do sistema de medição de desempenho.

Um ponto importante a ser salientado é que não foi encontrado na literatura pesquisada um modelo específico para a maturidade do sistema de medição de desempenho para a gestão da cadeia de suprimentos. Ambos os modelos supracitados, foram desenvolvidos

Quadro 2. Sistemas de medição de desempenho para a gestão da cadeia de suprimentos.

\begin{tabular}{|c|c|}
\hline Autores & Características \\
\hline $\begin{array}{l}\text { Andersson, Aronsson e } \\
\text { Storhagen (1989) }\end{array}$ & Focado em processos, satisfação dos clientes e medição financeira. \\
\hline Van Hoek (1998) & $\begin{array}{l}\text { Medidas relacionadas a custos logísticos, atendimento aos clientes, flexibilidade e } \\
\text { nível de comprometimento na cadeia de suprimentos. }\end{array}$ \\
\hline Beamon (1999) & $\begin{array}{l}\text { Focado na medição de processos básicos, flexibilidade, satisfação dos clientes e } \\
\text { financeira. }\end{array}$ \\
\hline Geary e Zonnenberg (2000) & Medidas relacionadas ao desempenho financeiro, flexibilidade e atendimento aos clientes. \\
\hline Holmberg (2000) & $\begin{array}{l}\text { Proposta de um sistema de medição de desempenho holístico para a gestão da cadeia } \\
\text { de suprimentos. Mais relacionado à estrutura de um sistema de medição para a gestão } \\
\text { da cadeia. }\end{array}$ \\
\hline Brewer e Speh (2000) & $\begin{array}{l}\text { Baseado no Balanced Scorecard e tem medidas ligadas ao valor oferecido aos clientes, } \\
\text { nível de serviços, colaboração, custos, processos e parceria na cadeia de suprimentos. }\end{array}$ \\
\hline Pires e Aravechia (2001) & Medidas focadas na satisfação dos clientes, processos básicos, flexibilidade e financeira. \\
\hline $\begin{array}{l}\text { Gunasekaran, Patel e } \\
\text { Tirtiroglu (2001) }\end{array}$ & $\begin{array}{l}\text { Foco na medição dos processos da cadeia, desempenho financeiro, nível de serviço } \\
\text { aos clientes. Flexibilidade e iniciativas de parcerias na cadeia. }\end{array}$ \\
\hline Chan et al. (2003) & $\begin{array}{l}\text { Sistema de medição de desempenho que considera uma estrutura desdobrada em } \\
\text { processos e subprocessos de acordo com as principais áreas de uma cadeia de } \\
\text { suprimento. Mais relacionado à estrutura de um sistema de medição de desempenho } \\
\text { para a gestão da cadeia. }\end{array}$ \\
\hline Bhagwat e Sharma (2007) & $\begin{array}{l}\text { Focado em processos, desempenho financeiro, nível de serviço, flexibilidade e } \\
\text { parcerias. Baseado na estrutura do Balanced Scorecard. }\end{array}$ \\
\hline $\begin{array}{l}\text { Supply-Chain Council } \\
\qquad(2008)\end{array}$ & $\begin{array}{l}\text { Baseado nos quarto processos do modelo do Supply Chain Operations Reference } \\
\text { (SCOR) - (planejar, adquirir, produzir e atender). Segue os atributos de } \\
\text { responsividade, agilidade, confiabilidade, custos e recursos. }\end{array}$ \\
\hline
\end{tabular}


para a maturidade do ponto de vista do negócio de uma organização.

\section{O Alinhamento entre a maturidade dos sistemas de medição de desempenho e a maturidade da gestão da cadeia de suprimentos}

Nesta seção, será apresentado o modelo teórico de alinhamento entre a maturidade dos sistemas de medição de desempenho e a maturidade da gestão da cadeia de suprimentos, construído a partir da revisão bibliográfica. O processo de desenvolvimento deste modelo seguiu as seguintes etapas:

- Identificação das dimensões da maturidade da gestão da cadeia de suprimentos;

- Identificação das dimensões da maturidade dos sistemas de medição de desempenho; e

- Associação entre as dimensões da maturidade da gestão da cadeia de suprimentos e da maturidade dos sistemas de medição de desempenho.

Baseado nos modelos de maturidade apresentados no Quadro 1, onze dimensões de maturidade da gestão da cadeia de suprimentos foram identificadas, considerando como base o modelo de Lockamy III e McCormack (2004) mais as dimensões que foram consideradas por outros autores. Por este motivo, esse modelo foi utilizado como a base para o desenvolvimento do modelo teórico de alinhamento entre a maturidade dos sistemas de medição de desempenho e a maturidade da gestão da cadeia de suprimentos. Adicionalmente, as dimensões que foram consideradas pelos outros autores, conforme apresenta o Quadro 1, mas não foram consideradas por Lockamy III e McCormack (2004), também foram incluídas no modelo base de maturidade para a gestão da cadeia de suprimentos, buscando-se, desta forma, ter um conjunto mais robusto de dimensões para o desenvolvimento do modelo teórico objeto deste estudo.

A Figura 1 apresenta as onze dimensões identificadas. À medida que essas dimensões evoluem ao longo do tempo, maior se torna o nível de integração e competências da gestão da cadeia de suprimentos.

As características de cada uma das dimensões encontradas são:

- Custos: está associada ao nível de custos e estoques da cadeia de suprimentos;

- Clientes: está associada ao foco dado aos clientes dentro da gestão da cadeia como também ao nível de satisfação dos clientes;

- Processos: refere-se à formalização, integração, estruturação dos processos dentro da cadeia;

- Tecnologia e ferramentas: está associada à existência de sistemas de informação e ferramentas para apoio à gestão da cadeia, como ferramentas estatísticas para previsão de demanda e sistemas de informações para gestão da cadeia entre outros;

- Colaboração: refere-se ao compartilhamento de informações, ganhos e de recursos entre os membros da cadeia, comunicação e a outras

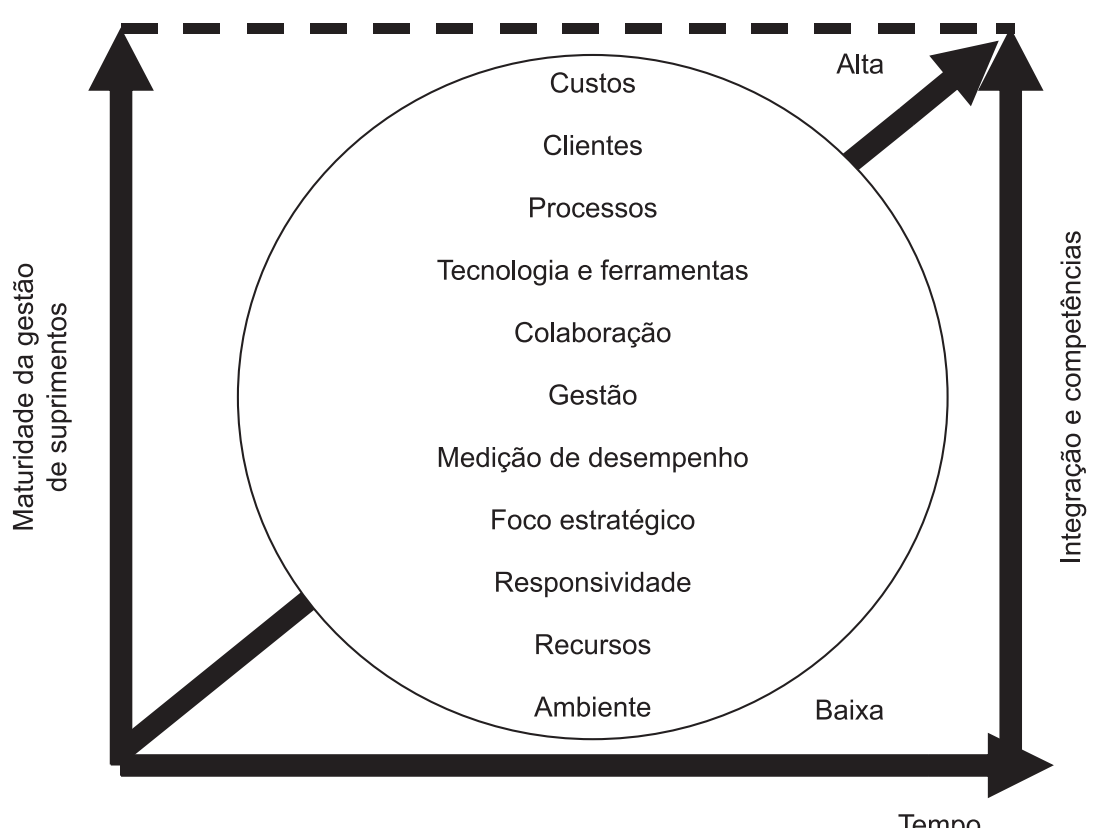

Figura 1. Dimensões de Maturidade da Gestão da Cadeia de Suprimentos. 
iniciativas de atuação conjunta dentro da cadeia, como o desenvolvimento de produtos e planejamento;

- Gestão: está associada ao nível de excelência na gestão de projetos dentro da cadeia de suprimentos, gestão de riscos e, também, ao nível de consciência e capacitação de gestão de cadeia de suprimentos pela equipe de gestão;

- Medição de desempenho: está associada à extensão da medição do desempenho da gestão da cadeia de suprimentos;

- Foco estratégico: refere-se à intenção estratégica que é dada à gestão da cadeia de suprimentos por parte da empresa-foco da cadeia e por parte de seus membros;

- Responsividade: está associada à velocidade com a qual a cadeia de suprimentos responde às mudanças do ambiente, exigindo um atendimento em termos de volume e mix dos produtos fornecidos por ela;

- Recursos: está associada aos tipos de recursos empregados na cadeia de suprimentos, sendo eles comuns (necessários para execução dos processos dentro da cadeia) e competitivos (geram vantagem competitiva e são difíceis de serem empregados pelas cadeias concorrentes devido aos seus diferenciais); e

- Ambiente: refere-se às questões de regulamentação e incentivos de créditos que favorecem o melhor desempenho da cadeia de suprimentos.
Em relação aos sistemas de medição de desempenho para a gestão da cadeia de suprimentos, de acordo com a literatura pesquisada, nota-se que eles são mais focados no escopo de medição dentro da cadeia de suprimentos. O fato é que o escopo de medição de desempenho é apenas uma das dimensões a serem consideradas na evolução de um sistema de medição, não sendo suficiente para caracterizar a maturidade deste sistema. Outras dimensões também devem ser levadas em consideração, como a coleta e armazenagem de dados, uso dos indicadores, comunicação dos resultados e qualidade do processo de medição.

Desta forma, para o desenvolvimento do modelo teórico objeto deste estudo, foi utilizado o modelo de Wettstein e Kueng (2002) devido ao fato de estar mais alinhado às estruturas dos modelos de maturidade propostos para a gestão da cadeia de suprimentos, os quais consideram características das dimensões para cada nível de maturidade, assim como segue o modelo de Wettstein e Kueng (2002) para a maturidade dos sistemas de medição de desempenho. Desta forma, para a maturidade dos SMDs, as dimensões consideradas são apresentadas por meio da Figura 2.

De acordo com a análise destas seis dimensões, à medida que elas evoluem em termos de sua maturidade, maior se torna a robustez de um sistema de medição de desempenho. As características das seis dimensões da maturidade dos sistemas de medição de desempenho são:

- Escopo de medição: refere-se basicamente às medidas de desempenho aplicadas na gestão da cadeia de suprimentos e a sua abrangência de medição;

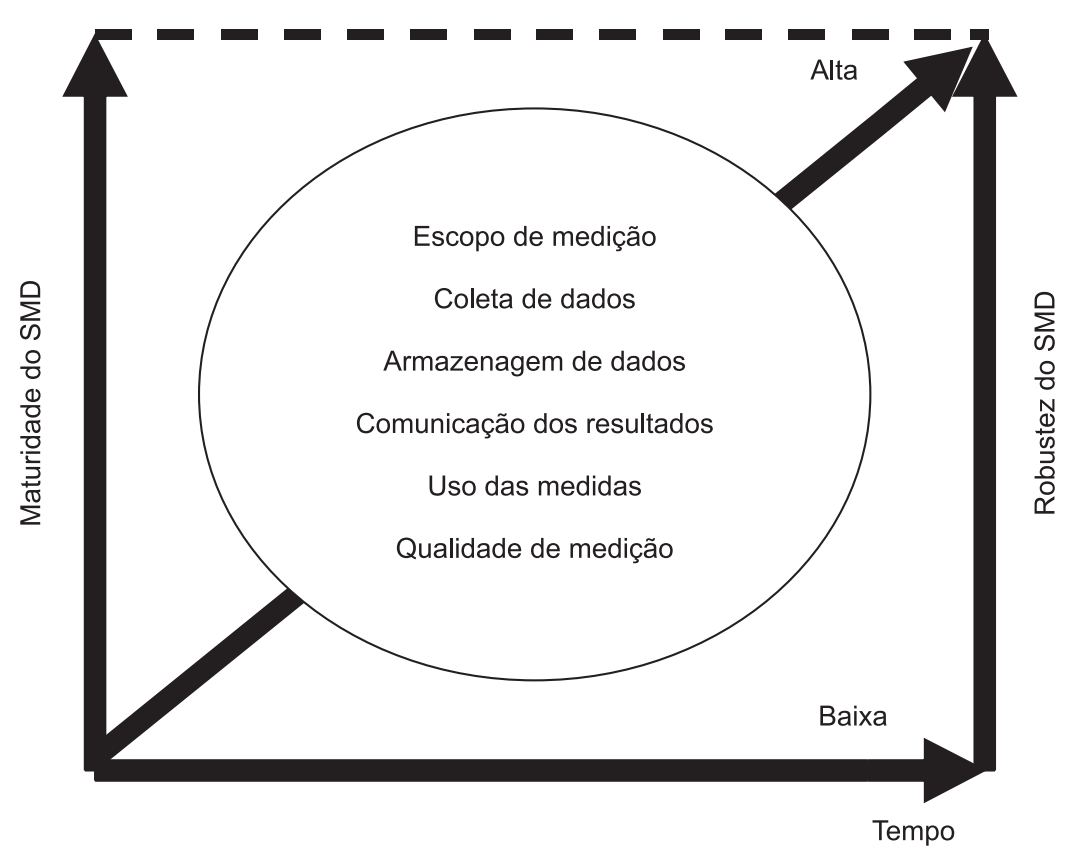

Figura 2. Dimensões de Maturidade dos Sistemas de Medição de Desempenho. 
- Coleta de dados: está associada à forma pela qual se efetiva a coleta de dados para a realização da medição de desempenho;

- Armazenagem de dados: refere-se à forma de como os dados referentes à medição de desempenho são armazenados;

- Comunicação dos resultados: está associada à forma e à extensão que se dá na comunicação dos resultados obtidos pelos indicadores de desempenho;

- Uso das medidas: está associada ao nível de uso e aplicação das medidas de desempenho na gestão da cadeia de suprimentos; e

- Qualidade de medição: refere-se ao processo de medição de desempenho, mais especificamente, à frequência, à forma e à rotina de melhoria pela qual ele se efetiva.

O modelo teórico de alinhamento entre a maturidade dos sistemas de medição de desempenho e a maturidade da gestão da cadeia de suprimentos é uma combinação das Figuras 1 e 2 . Foram considerados três estágios de maturidade: Inicial, Intermediário e Avançado. O alinhamento em três níveis foi necessário devido à diferença da quantidade de níveis existentes entre os modelos de maturidade da gestão da cadeia de suprimentos e os modelos de maturidade dos sistemas de medição de desempenho.

A Figura 3 apresenta o modelo teórico que é a base conceitual da pesquisa de campo realizada. A maturidade da gestão da cadeia de suprimentos bem como a dos sistemas de medição de desempenho evoluem em três níveis. Para cada um dos níveis, as onze dimensões da maturidade da gestão da cadeia de suprimentos e as seis dimensões da maturidade dos sistemas de medição de desempenho possuem diferentes características.

As características para a maturidade da gestão da cadeia de suprimentos em cada nível de maturidade são:

- Inicial: prevalência de altos custos na cadeia, baixa satisfação dos clientes, processos desestruturados e desintegrados, falta de colaboração entre os membros, ausência de tecnologias e ferramentas para a previsão de demanda e outras atividades, ausência de foco estratégico na cadeia, gestão de projetos na cadeia de suprimentos pouco atuante, ausência de gestão de riscos, ausência de medição de desempenho ao longo da cadeia, falta de regulamentação e

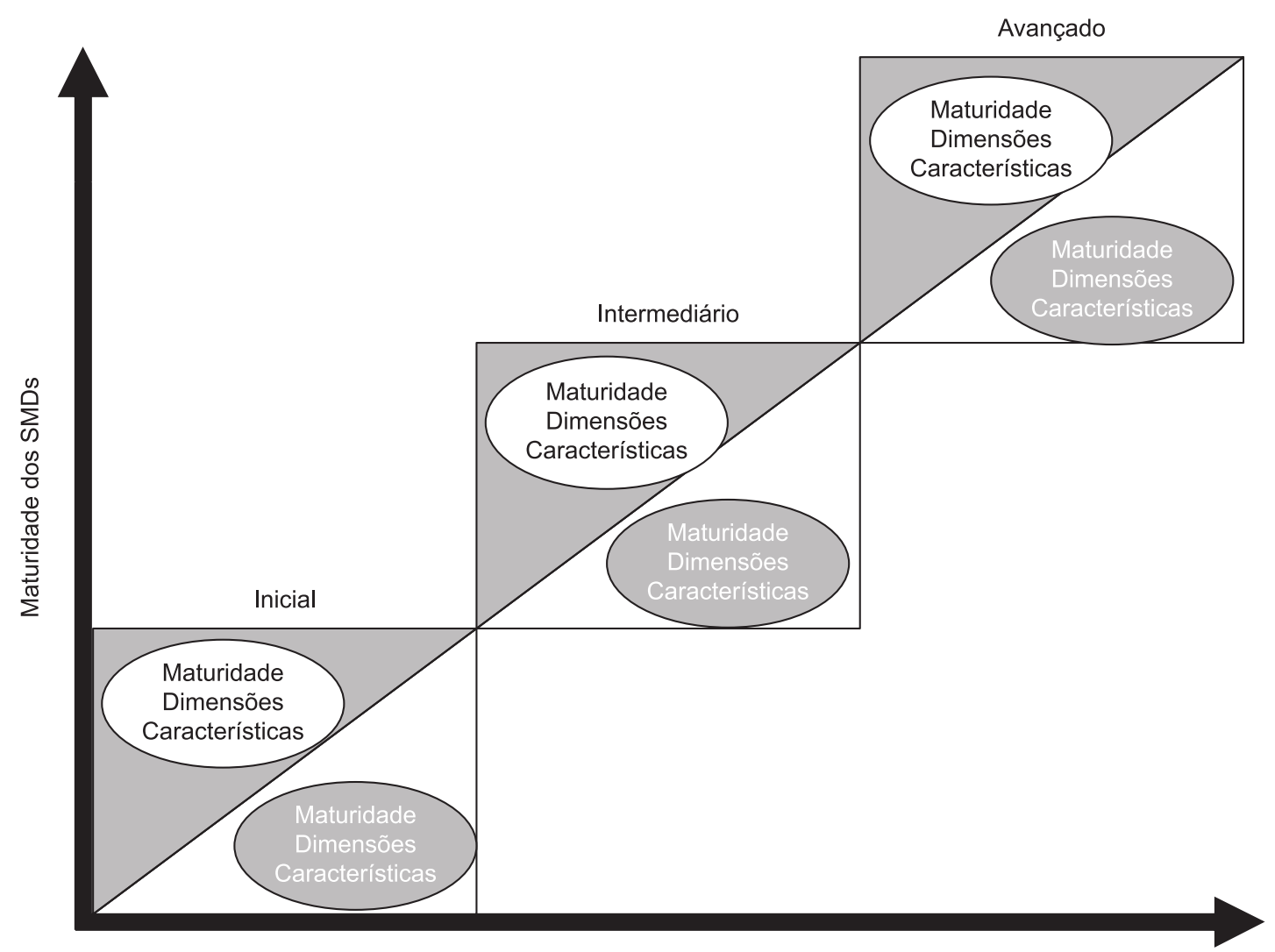

Maturidade da gestão da cadeia de suprimentos

Figura 3. Modelo teórico de alinhamento entre a maturidade dos SMDs e a maturidade da gestão da cadeia de suprimentos. 
linhas de crédito como elementos de apoio para a cadeia e uso de recursos básicos e comuns;

- Intermediário: busca pela redução de custos na cadeia, média satisfação dos clientes, processos documentados e definidos iniciando um foco mais horizontal ao longo da cadeia, espírito de cooperação entre as funções relativas à gestão da cadeia de suprimentos na empresa-foco, uso de tecnologias e ferramentas estatísticas para previsão de demanda e outras atividades, cadeia como foco estratégico, consciência, visão e competência em gestão da cadeia de suprimentos por parte dos colaboradores, boas práticas de gestão de projetos, início de uma gestão de riscos, existência de medição de desempenho, início de regulamentações e linhas de crédito que auxiliem a cadeia de suprimentos e uso de recursos adequados, porém ainda sem diferenciais na cadeia de suprimentos; e

- Avançado: cadeia com excelência em custos, foco total no cliente e alto índice de satisfação, processos totalmente integrados e estruturados ao longo da cadeia, amplo uso de sistemas de informações, compartilhamento de ganhos e informações entre os membros da cadeia, excelência na gestão de projetos e de riscos, ampla medição de desempenho, cadeia de suprimentos vista como fator de competitividade perante outras cadeias, atuação responsiva perante as variações de demanda originadas pelos clientes, ampla regulamentação e linhas de crédito para fomento da cadeia de suprimentos.

Já as características para a maturidade dos sistemas de medição de desempenho são:

- Inicial: medição de desempenho com foco financeiro, coleta de dados manual, armazenagem de dados desordenada, comunicação pontual dos resultados, falta de definição em relação ao uso dos indicadores de desempenho e qualidade do processo de medição não definida;

- Intermediário: medição de desempenho ainda com foco financeiro, porém com o início de alguns outros enfoques de medição, coleta e armazenagem de dados automatizados focados em dados financeiros, sendo as outras informações coletadas manualmente e armazenadas de forma dispersa, comunicação dos resultados concentrada para a alta e média gerência, uso dos indicadores e preocupação com a qualidade do processo de medição ocorrem de forma mais rotineira, respeitando determinado nível de disciplina; e
- Avançado: ampla medição de desempenho, abrangendo os stakeholders presentes na gestão da cadeia de suprimentos, coleta e armazenagem de dados e informações ocorre por meio de uma base sistêmica, ampla comunicação dos resultados, amplo uso dos indicadores servindo como base para planejamento e gestão da cadeia e melhoria contínua em relação ao processo de medição de desempenho, buscando seu aperfeiçoamento e a implantação de novas tecnologias.

Baseado no modelo teórico apresentado, para melhor orientação da pesquisa realizada, duas proposições teóricas foram criadas. Essas proposições são:

- Proposição 1: A evolução da gestão da cadeia de suprimentos ocorre a partir de um nível inicial até um nível avançado em relação aos custos, clientes, processos, tecnologia e ferramentas, colaboração, gestão, medição de desempenho, foco estratégico, responsividade, recursos e ambiente; e

- Proposição 2: A evolução da maturidade dos sistemas de medição de desempenho na gestão da cadeia de suprimentos, ocorre simultaneamente à evolução da maturidade desta gestão, saindo de um nível inicial para um nível avançado em relação ao seu escopo de medição, coleta de dados, armazenagem de dados, comunicação dos resultados, uso das medidas e qualidade do processo de medição.

\section{Método de pesquisa}

Antes da escolha do método de pesquisa é importante a definição da abordagem de pesquisa a ser adotada. A abordagem de pesquisa pode ser quantitativa ou qualitativa. A diferenciação entre as abordagens em termos da presença ou ausência da quantificação é um erro. A principal característica da pesquisa qualitativa em relação à pesquisa quantitativa está na sua ênfase na perspectiva do indivíduo sobre o problema de pesquisa (BRYMAN, 1989). A pesquisa qualitativa está mais ligada ao aspecto fenomenológico, na busca de significados realizando gerações de hipóteses. Já a pesquisa quantitativa, familiariza-se mais com os fatos sociais, preocupando-se mais com o teste de hipóteses (AMARATUNGA et al., 2002).

Para Amaratunga et al. (2002), as principais fraquezas da abordagem quantitativa é que os métodos tendem a ser mais inflexíveis e artificiais, além de não serem muito eficazes no entendimento de processos ou à significância que as pessoas dão para as ações. Além disso, a abordagem quantitativa não contribui muito para a geração de novas teorias. Já, quanto à abordagem 
qualitativa, esses autores entendem como fraquezas a coleta de dados, a qual pode ser difícil e requerer mais recursos, a análise e interpretação dos dados que podem ser mais complexos e o árduo controle em relação ao progresso e à finalização do processo de pesquisa. Em relação às técnicas de pesquisa, associadas a essas abordagens, Bryman (1989) considera que, na pesquisa qualitativa, as principais técnicas de pesquisa são a observação participante e as entrevistas não estruturadas e semiestruturadas, sendo que essas técnicas, geralmente estão associadas com a coleta de documentos. Quanto às técnicas da abordagem quantitativa, segundo Bryman e Bell (2007), são utilizados a entrevista estruturada, questionários e a observação estruturada.

No tocante à pesquisa realizada, a abordagem escolhida foi qualitativa, devido a uma maior preocupação com o fenômeno e a realidade da relação entre a maturidade dos SMDs e a maturidade da gestão da cadeia de suprimentos, à busca dos entendimentos e significados deste fenômeno e à ênfase dada à perspectiva do objeto de estudo, em que os entendimentos foram obtidos a partir da sua perspectiva. Outro fato é que esse conhecimento desta relação ainda é muito pouco explorado, razão do ineditismo desta pesquisa.

Em relação aos métodos de pesquisa, os utilizados na engenharia de produção podem ser: survey, estudo de caso, pesquisa-ação, modelagem/simulação e pesquisa experimental (MIGUEL, 2007). Quanto ao estudo de caso, ele é uma investigação empírica que aborda um fenômeno contemporâneo dentro de seu contexto da vida real especialmente quando os limites entre o fenômeno e o contexto não estão claramente definidos (YIN, 2005). O estudo de caso inclui tanto estudos de caso único como também estudos de caso múltiplos e se refere aos estudos realizados a partir de duas unidades de análise (YIN, 2005). O estudo de caso pode ser usado para os seguintes propósitos: estudos exploratórios, construção de teorias, testes de teorias e refinamento e extensão de teorias (VOSS; TSIKRIKTSIS; FROHLICH, 2002).

No caso desta pesquisa, adotou-se o método estudo de caso múltiplo exploratório, por meio do entendimento da relação entre os níveis de maturidade dos sistemas de medição de desempenho e os da gestão da cadeia de suprimentos, buscando-se com este estudo exploratório, uma contribuição para a proposição de um modelo para entendimento e abordagem da problemática estudada. A justificativa pela escolha deste método de estudo de caso se dá pelo fato de que a pesquisa adotou uma abordagem qualitativa, devendo, portanto, o método possuir maior grau de flexibilidade para obter informações a partir da perspectiva do objeto de estudo. Outro ponto que contribuiu para a escolha deste método é que não existe uma definição clara dos limites entre o contexto a ser estudado, que se refere à relação entre os SMDs e sua maturidade e a maturidade da gestão da cadeia de suprimentos e o fenômeno que seria o que ocorre na existência desta relação em uma gestão da cadeia de suprimentos. A técnica de pesquisa escolhida foi a de entrevista semiestruturada, a qual foi guiada por meio de um protocolo de pesquisa, elaborado com base no modelo teórico e proposições teóricas. Seuring (2008) enfatiza isso para o caso de pesquisas em gestão da cadeia de suprimentos.

Quanto às unidades de análise, foram utilizadas três empresas pertencentes a três cadeias de suprimentos distintas. Essas empresas exercem o papel de empresa-foco destas cadeias, na qual exerce a coordenação das atividades a montante e a jusante da cadeia.

As unidades de análise, nas quais o método de pesquisa foi aplicado, foram escolhidas com base no nível de maturidade da gestão da cadeia de suprimentos. Previamente foi feita uma pesquisa para verificar em qual nível de maturidade a gestão da cadeia de suprimentos da empresa-foco de cada cadeia se encontrava. Este critério foi adotado tendo em vista que, para uma análise mais apropriada do modelo teórico proposto, era importante que cada unidade de análise se enquadrasse em cada um dos três níveis de maturidade estabelecidos no modelo. As pessoas entrevistadas nas unidades de análise foram gerentes e diretores responsáveis pela gestão da cadeia de suprimentos, tanto a montante como a jusante da empresa-foco. As empresas pesquisadas foram denominadas de Empresa A, B e C.

A Empresa A é subsidiária no Brasil de uma multinacional de origem norte-americana. Ela atua no setor metalúrgico, com uma planta localizada no município de Guarulhos (SP). Seus principais clientes são do ramo industrial. A empresa fornece materiais e equipamentos especiais para soldagem. Uma parte é importada e outra produzida no País. Os principais fornecedores são empresas das indústrias metal-mecânica e química.

A Empresa B é subsidiária no Brasil de uma multinacional com origem norte-americana. Ela é atua no setor farmacêutico - nutrição humana -, sua planta está localizada no município de São Bernardo do Campo (SP) e atende clientes como farmácias e redes de supermercados. Os principais fornecedores são empresas das indústrias químicas, embalagem e de alimentos.

A Empresa C é subsidiária no Brasil de uma multinacional com origem norte-americana. Ela atua no setor químico e tem uma planta localizada no município de Jundiaí (SP). Os seus principais clientes são empresas da indústria automotiva, construção e metal-mecânica. Os seus principais fornecedores são empresas da indústria química. 


\section{Resultados empíricos}

Como já mencionado, a coleta de dados, por meio de entrevistas semiestruturadas, foi guiada por um protocolo de pesquisa. A base para o desenvolvimento do protocolo foi o modelo teórico, apresentado na Figura 3. As características das dimensões das três empresas estudadas estão apresentadas no Quadro 3.

De acordo com as evidências do Quadro 3, as dimensões de colaboração, tecnologia, gestão, responsividade, recursos, ambiente, custos e clientes da Empresa A estão num nível Inicial de maturidade. Já as dimensões de processos, medição de desempenho e foco estratégico enquadraram-se num nível Intermediário de maturidade. Desta forma, a maturidade da gestão da cadeia de suprimentos da Empresa A foi enquadrada no nível Inicial, devido ao fato de que grande parte das dimensões esteve presente neste nível.

Em relação à Empresa B, as evidências levaram para uma interpretação diferente. De acordo com os dados do Quadro 3, as dimensões de gestão, tecnologia e ferramentas, colaboração, processos, clientes, custos, foco estratégico, recursos e ambiente enquadraram-se no nível Avançado de maturidade.

Quadro 3. Resultados empíricos sobre a maturidade da gestão da cadeia de suprimentos.

\begin{tabular}{|c|c|c|c|}
\hline Dimensões & Empresa A & Empresa B & Empresa C \\
\hline Custos & $\begin{array}{l}\text { Altos custos e forte pressão } \\
\text { por redução de custos. }\end{array}$ & $\begin{array}{l}\text { Excelência em custos. Maior parte } \\
\text { das oportunidades de redução de } \\
\text { custos já foi explorada. }\end{array}$ & $\begin{array}{l}\text { Pressão por redução de custos. } \\
\text { Redução vem sendo efetuada, } \\
\text { porém pode ser melhorada. }\end{array}$ \\
\hline Clientes & $\begin{array}{l}\text { Falta de práticas de } \\
\text { relacionamento e foco no } \\
\text { cliente. }\end{array}$ & $\begin{array}{l}\text { Foco no cliente e forte parceria } \\
\text { com eles. Alto nível de satisfação. } \\
\text { Índice de } 95 \%\end{array}$ & $\begin{array}{l}\text { Foco no cliente por divisão } \\
\text { de mercado. Alto índice de } \\
\text { satisfação acima de } 95 \%\end{array}$ \\
\hline Processos & $\begin{array}{l}\text { Alguns processos são } \\
\text { formalizados e estruturados. } \\
\text { Integração interna. }\end{array}$ & $\begin{array}{l}\text { Processos definidos e } \\
\text { formalizados. Integração externa } \\
\text { com uso de troca eletrônica de } \\
\text { dados (EDI). }\end{array}$ & $\begin{array}{l}\text { Processos definidos e } \\
\text { formalizados. Uso de EDI e } \\
\text { para integração externa. }\end{array}$ \\
\hline $\begin{array}{l}\text { Tecnologias e } \\
\text { ferramentas }\end{array}$ & $\begin{array}{l}\text { Sistema integrado de } \\
\text { gestão. No entanto faltam } \\
\text { ferramentas de inteligência. }\end{array}$ & $\begin{array}{l}\text { Sistema de gestão integrado } \\
\text { (SAP). Uso de ferramentas de } \\
\text { inteligência como o Advanced } \\
\text { Planner and Optimizer e Route } \\
\text { Planner. }\end{array}$ & $\begin{array}{l}\text { Uso de sistema de gestão } \\
\text { integrada dos processos (SAP). } \\
\text { Ausência de ferramentas de } \\
\text { inteligência para auxílio à } \\
\text { gestão da cadeia. }\end{array}$ \\
\hline Colaboração & $\begin{array}{l}\text { Sem colaboração em termos } \\
\text { de ganhos e informações. }\end{array}$ & $\begin{array}{l}\text { Compartilhamento de } \\
\text { informações com clientes. } \\
\text { Ganhos são compartilhados com } \\
\text { distribuidores e fornecedores. }\end{array}$ & $\begin{array}{l}\text { Colaboração parcial na cadeia } \\
\text { em termos de ganhos e de } \\
\text { informações. Ocorre somente } \\
\text { a jusante. }\end{array}$ \\
\hline Gestão & $\begin{array}{l}\text { Gestão de projetos e riscos } \\
\text { não foram observados. }\end{array}$ & $\begin{array}{l}\text { Uso do Project Management Book } \\
\text { para gestão de projetos. Planos de } \\
\text { contingência para gestão de riscos. }\end{array}$ & $\begin{array}{l}\text { Gestão de projetos alinhados } \\
\text { a programas } 6 \text { sigma. Gestão } \\
\text { de riscos estruturada. }\end{array}$ \\
\hline $\begin{array}{l}\text { Medição de } \\
\text { desempenho }\end{array}$ & $\begin{array}{l}\text { Foco na medição financeira } \\
\text { com algumas poucas } \\
\text { medidas não financeiras. }\end{array}$ & $\begin{array}{l}\text { Foco na medição financeira. } \\
\text { Processos são medidos, mas não } \\
\text { de uma forma abrangente. }\end{array}$ & $\begin{array}{l}\text { Foco na medição financeira } \\
\text { com alguns poucos } \\
\text { indicadores não financeiros. }\end{array}$ \\
\hline Foco estratégico & $\begin{array}{l}\text { Gestão da cadeia como um } \\
\text { elemento importante na } \\
\text { estratégia da empresa. }\end{array}$ & $\begin{array}{l}\text { Foco estratégico muito bem } \\
\text { definido. Ser best in class em } \\
\text { gestão da cadeia de suprimentos. }\end{array}$ & $\begin{array}{l}\text { Foco estratégico definido. } \\
\text { Busca da excelência em } \\
\text { gestão da cadeia. }\end{array}$ \\
\hline Responsividade & $\begin{array}{l}\text { Baixa responsividade em } \\
\text { relação ao atendimento de } \\
\text { alguns mix de produtos. }\end{array}$ & $\begin{array}{l}\text { Dimensão que necessita de } \\
\text { melhoria na cadeia. Cadeia ainda } \\
\text { depende de estoques para garantir } \\
\text { tempos de resposta exigidos. }\end{array}$ & $\begin{array}{l}\text { Responsividade precisa } \\
\text { ser melhorada. Cadeia a } \\
\text { montante impede a empresa } \\
\text { de ser mais responsiva aos } \\
\text { clientes. }\end{array}$ \\
\hline Recursos & $\begin{array}{l}\text { Não existem recursos } \\
\text { diferenciados na cadeia. }\end{array}$ & $\begin{array}{l}\text { Centros avançados de } \\
\text { desenvolvimento geram } \\
\text { diferenciação dos produtos na } \\
\text { cadeia. }\end{array}$ & $\begin{array}{l}\text { Recursos são adequados } \\
\text { à cadeia de suprimentos. } \\
\text { Algumas tecnologias pode- } \\
\text { riam ser implementadas. }\end{array}$ \\
\hline Ambiente & $\begin{array}{l}\text { Não existem incentivos } \\
\text { em relação à importação } \\
\text { de produtos causando } \\
\text { dificuldades de competição. }\end{array}$ & $\begin{array}{l}\text { Existência de regulamentações } \\
\text { que favorecem a competição no } \\
\text { mercado. }\end{array}$ & $\begin{array}{l}\text { Início de melhoria no } \\
\text { sistema de regulamentação } \\
\text { do segmento em relação ao } \\
\text { sistema de tributos. } \\
\end{array}$ \\
\hline
\end{tabular}


Somente as dimensões de responsividade e medição de desempenho estiveram no nível inferior de maturidade, o Intermediário. Seguindo a mesma lógica da Empresa A, a maturidade da gestão da cadeia de suprimentos foi considerada como sendo do nível Avançado.

No tocante à Empresa $\mathrm{C}$, conforme evidências apresentadas por meio do Quadro 3, apenas quatro dimensões estiveram no nível Avançado de maturidade. São elas: clientes, processos, foco estratégico e gestão. As outras dimensões, como custos, ambiente, recursos, responsividade, medição, tecnologia e colaboração, estiveram presentes no nível Intermediário. Utilizando-se do mesmo critério das Empresas A e B, a Empresa C foi enquadrada no nível Intermediário de maturidade.

Em relação à maturidade do sistema de medição de desempenho, o Quadro 4 apresenta as evidências coletadas nas três empresas estudadas. Elas permitiram classificar a maturidade dos SMDs das três empresas estudadas.

De acordo com as evidências no Quadro 4, para a Empresa A, as dimensões de comunicação de resultados, uso dos indicadores de desempenho e qualidade do processo de medição estão num nível Inicial de maturidade do SMD. Por outro lado, as dimensões de coleta de dados, escopo de medição e armazenagem de dados estão alinhadas ao nível Intermediário de maturidade. Neste caso, a maturidade do sistema de medição de desempenho da Empresa A é Inicial pelo fato do número de dimensões presente nos dois níveis ter sido o mesmo, o que, seria duvidoso enquadrar a maturidade no nível Intermediário, já que metade de suas dimensões ainda encontram-se num nível inferior.

Já para a Empresa B, as evidências mostram uma diferente situação. De acordo com essas evidências apresentadas no Quadro 4, as dimensões de coleta de dados e armazenagem de dados estão no nível Inicial. Por outro lado, as dimensões de escopo de medição e qualidade do processo de medição estão no nível Intermediário. Já, as dimensões de uso dos indicadores de desempenho e comunicação de resultados estão no nível Avançado. Desta forma, seguindo o mesmo critério aplicado anteriormente, a Empresa B está no nível Intermediário de maturidade.

No que diz respeito à Empresa $\mathrm{C}$, diferentemente das Empresas A e B, todas as dimensões estão alinhadas no nível Intermediário de maturidade. Desta forma, pode-se classificar a Empresa C no nível Intermediário de maturidade em relação ao sistema de medição de desempenho para a gestão da cadeia de suprimentos.

A Figura 4 apresenta uma síntese do estudo de caso. Ela ilustra a posição das três empresas em relação à maturidade da gestão da cadeia de suprimentos (eixo x) e à maturidade do sistema de

Quadro 4. Resultados empíricos sobre a maturidade dos SMDs.

\begin{tabular}{|c|c|c|c|}
\hline Dimensões & Empresa A & Empresa B & Empresa C \\
\hline Escopo de medição & $\begin{array}{l}\text { Foco nas medidas } \\
\text { financeiras. Medição limitada } \\
\text { em relação aos processos de } \\
\text { gestão da cadeia. }\end{array}$ & $\begin{array}{l}\text { Medição focada em medidas } \\
\text { financeiras. Alguns indicadores } \\
\text { não financeiros são usados na } \\
\text { gestão da cadeia. }\end{array}$ & $\begin{array}{l}\text { Foco na medição financeira. } \\
\text { Alguns poucos indicadores } \\
\text { não financeiros. }\end{array}$ \\
\hline Coleta de dados & $\begin{array}{l}\text { Parte dos dados coletados } \\
\text { manualmente e outra parte de } \\
\text { forma automatizada. }\end{array}$ & $\begin{array}{l}\text { Coleta de dados totalmente } \\
\text { manual. }\end{array}$ & $\begin{array}{l}\text { Coleta parcialmente manual e } \\
\text { parcialmente automatizada. }\end{array}$ \\
\hline $\begin{array}{l}\text { Armazenagem de } \\
\text { dados }\end{array}$ & $\begin{array}{l}\text { Alguns dados são } \\
\text { armazenados em sistemas } \\
\text { e outros em planilhas } \\
\text { eletrônicas dispersas. }\end{array}$ & $\begin{array}{l}\text { Todos os dados armazenados } \\
\text { em planilhas eletrônicas } \\
\text { dispersas. }\end{array}$ & $\begin{array}{l}\text { Grande parte dos dados } \\
\text { armazenados em base única. } \\
\text { Alguns dados armazenados } \\
\text { ainda em planilhas eletrônicas. }\end{array}$ \\
\hline $\begin{array}{l}\text { Comunicação dos } \\
\text { resultados }\end{array}$ & $\begin{array}{l}\text { Indicadores são divulgados } \\
\text { apenas para o alto nível } \\
\text { gerencial e não regularmente. }\end{array}$ & $\begin{array}{l}\text { Rotina estabelecida em } \\
\text { relação à divulgação dos } \\
\text { resultados para todos os } \\
\text { níveis, incluindo clientes e } \\
\text { fornecedores. }\end{array}$ & $\begin{array}{l}\text { Rotina de divulgação existente. } \\
\text { Porém sem definição a quem } \\
\text { são apresentados. Forma ruim } \\
\text { de divulgação por meio de } \\
\text { planilhas. }\end{array}$ \\
\hline $\begin{array}{l}\text { Uso dos indicadores } \\
\text { de desempenho }\end{array}$ & $\begin{array}{l}\text { Uso dos indicadores mensal e } \\
\text { não definido em relação a sua } \\
\text { utilidade. }\end{array}$ & $\begin{array}{l}\text { Indicadores são usados } \\
\text { semanalmente para } \\
\text { estabelecer planos de ação e } \\
\text { melhoria contínua. }\end{array}$ & $\begin{array}{l}\text { Indicadores são utilizados } \\
\text { mensalmente para estabe- } \\
\text { lecimento de planos de ação, } \\
\text { porém não existe um formato } \\
\text { estabelecido para isso. }\end{array}$ \\
\hline $\begin{array}{l}\text { Qualidade do } \\
\text { processo de medição }\end{array}$ & $\begin{array}{l}\text { Processo de medição não é } \\
\text { revisado continuamente e } \\
\text { sem definição. }\end{array}$ & $\begin{array}{l}\text { Processo de medição é revisto, } \\
\text { porém uma vez ao ano. }\end{array}$ & $\begin{array}{l}\text { Processo revisto anualmente, } \\
\text { porém ainda sem foco em } \\
\text { melhorias por meio de } \\
\text { tecnologias para o seu auxílio. }\end{array}$ \\
\hline
\end{tabular}


Maturidade dos casos

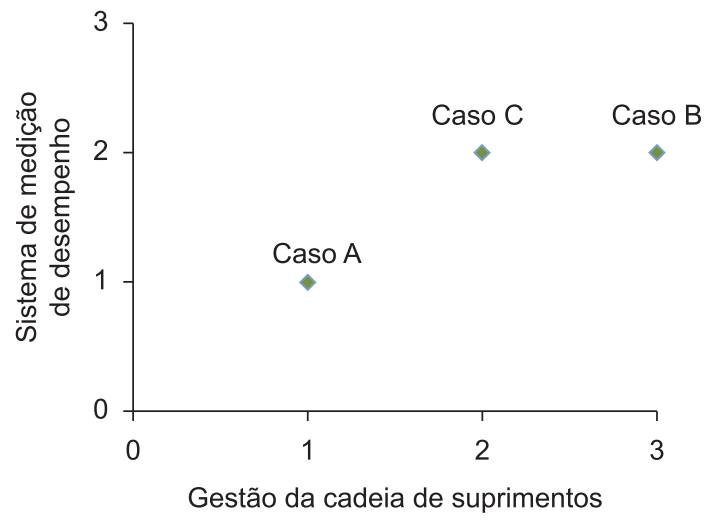

Figura 4. Enquadramento das três empresas na maturidade da gestão da cadeia de suprimentos e na maturidade do SMD.

medição de desempenho (eixo y). Os números 1, 2 e 3 estão associados aos níveis Inicial, Intermediário e Avançado de maturidade.

Cabe ressaltar que, para classificar os casos nos níveis de maturidade, as características observadas na pesquisa de campo foram comparadas com as características apresentadas nos estágios Inicial, Intermediário e Avançado do modelo proposto, conforme Figura 3. Tal modelo foi construído a partir das dimensões de maturidade presentes nas Figuras 1 e 2, cujos conteúdos são resultantes da pesquisa bibliográfica.

Conforme a Figura 4, observa-se que a Empresa A está alinhada na posição 1 para ambos os eixos, o que significa que a maturidade do sistema de medição de desempenho está alinhada à maturidade da gestão da cadeia de suprimentos, estando ambas no nível Inicial.

Diferentemente, a Empresa B encontra-se em diferentes posições no gráfico, 3 no eixo x e 2 no eixo y. Isto significa que a maturidade do sistema de medição de desempenho não está alinhada à maturidade da gestão da cadeia de suprimentos, estando esta última em um nível superior de maturação, o Avançado. Isto é um ponto ruim, pois significa que o sistema de medição de desempenho pode não estar suportando adequadamente a gestão da cadeia de suprimentos. O esperado é que a maturidade da gestão da cadeia de suprimentos acabe exigindo que a maturidade do SMD avance para que esta última possa ser suporte para a gestão da Empresa B. Quanto à Empresa C, as maturidades do sistema de medição de desempenho também estiveram alinhadas à maturidade da gestão da cadeia de suprimentos, estando presentes para ambos os eixos (x e y) na posição 3, o que significa que as duas maturidades encontram-se no nível Avançado.

\section{Conclusões}

Este artigo apresentou os resultados dos três casos estudados por meio da pesquisa de campo realizada em três empresas de seguimentos distintos, na busca de evidências acerca do relacionamento entre a maturidade do sistema de medição de desempenho e a maturidade da gestão da cadeia de suprimentos. A revisão da literatura demonstrou a inexistência de tal relacionamento e um modelo foi desenvolvido a partir da literatura existente sobre esses dois elementos. Com base neste modelo, duas proposições teóricas foram desenvolvidas, conforme apresentadas na seção 3 deste artigo.

A primeira proposição teórica foi confirmada em parte. Foi verificado nos casos estudados que as onze dimensões que caracterizam a maturidade da gestão da cadeia de suprimentos estavam presentes nos três casos estudados. No entanto, foi verificado que nem sempre estas dimensões estão num mesmo estágio de maturidade para uma mesma empresa.

$O$ fato das dimensões não estarem sempre no mesmo nível, talvez possa ser explicado pela a ausência de um olhar mais gerencial pelos praticantes em termos de se gerenciar a evolução da gestão da cadeia de suprimentos. Como visto na revisão da literatura, os modelos, por si sós, não contemplam todas as variáveis da maturidade, motivo pelo qual adotou-se, na construção do modelo teórico, a junção de todas as dimensões propostas na literatura pesquisada. Mesmo que a maior parte das dimensões esteja presente num determinado nível de maturidade e a menor parte em outro nível, é preciso investigar quais dimensões realmente são cruciais para que a maturidade tenha um efeito no desempenho da gestão da cadeia de suprimentos, uma vez que os modelos, até então, na literatura pesquisada, preveem níveis de maturidade de uma forma estática, não se levando em consideração que as dimensões poderiam variar pelos estágios de maturidade, de acordo com as suas características.

A segunda proposição teórica também foi confirmada em parte. Nos três casos estudados, foi identificado que as seis dimensões foram verificadas como elementos da maturidade do sistema de medição de desempenho. Portanto, da mesma forma como ocorreu com a maturidade da gestão da cadeia de suprimentos, nem sempre elas estão presentes num mesmo nível de maturidade.

Desta forma, pode-se concluir que a maturidade do sistema de medição de desempenho evolui em termos das seis dimensões propostas pelo modelo teórico, com a ressalva de que, desde o nível Inicial de maturidade, alguns indicadores não financeiros já fazem parte do escopo de medição. Foi constatado também que as seis dimensões podem estar em níveis diferentes de maturidade para um mesmo sistema de medição de desempenho.

Da mesma forma que ocorreu com a maturidade da gestão da cadeia de suprimentos, as dimensões apresentaram-se em níveis diferentes, sendo então 
necessárias mais pesquisas para entender melhor quais dimensões são efetivamente cruciais para se determinar o exato nível de maturidade de um sistema de medição de desempenho.

Outro ponto importante em relação à Proposição 2 é a evolução paralela entre a maturidade do sistema de medição e a maturidade da gestão da cadeia de suprimentos. Conforme ilustra a Figura 4, após a análise dos três casos, foi verificado que no Caso A e no Caso $\mathrm{C}$ a maturidade do sistema de medição esteve presente no mesmo nível de maturidade da gestão da cadeia de suprimentos. Porém, no Caso B, a maturidade da gestão da cadeia de suprimentos esteve num estágio superior à maturidade do sistema de medição, o que caracteriza um desalinhamento.

O que pode ocorrer é que, embora a maturidade da gestão da cadeia e a maturidade do sistema de medição em algum momento fiquem em uma posição harmoniosa, a primeira se torne superior à segunda, exigindo, posteriormente, um avanço do nível de maturidade do sistema de medição.

Certamente, mais pesquisas são necessárias para melhorar o entendimento e confirmação do modelo proposto, mas, de uma forma geral, as maturidades dos dois elementos precisam evoluir de forma harmônica do nível Inicial para o Avançado, conforme modelo teórico apresentado por meio da Figura 3. Pode ocorrer que as maturidades podem não estar alinhadas em determinado momento, mas é importante saber as consequências disso. $\mathrm{O}$ foco foi de alinhamento entre as duas dimensões. Naturalmente que se pressupõe, como encontrado na literatura pesquisada, um alinhamento estratégico e com o ambiente externo da organização, mas isto não foi tratado nesta pesquisa.

Cabe salientar que este esforço de pesquisa limitou-se a explorar o relacionamento entre a maturidade da gestão da cadeia de suprimentos e a maturidade dos sistemas de medição de desempenho, por meio do alinhamento de suas características em comum a partir de uma abordagem de pesquisa qualitativa, não se pretendendo, para este momento, estabelecer qualquer correlação quantitativa de cunho estatístico entre essas duas dimensões e o resultado do desempenho da cadeia. A partir deste estudo, que proporciona melhor entendimento das dimensões, tal relacionamento poderá ser investigado em pesquisas futuras de caráter quantitativo.

Este artigo buscou trazer uma abordagem inédita por meio da proposição de um modelo que relaciona a maturidade dos SMDs com a maturidade da gestão da cadeia de suprimentos. Embora mais pesquisas sobre o tema e o objeto de estudo sejam necessárias, a importância do artigo está no estabelecimento inicial do relacionamento entre essas duas maturidades, algo até então não explorado pela literatura existente. Como principal contribuição, está sua abordagem inicial, que permitirá aos pesquisadores o desenvolvimento de mais pesquisas relacionadas ao assunto, utilizando-se do modelo proposto como base para esse propósito. Para os praticantes da gestão da cadeia de suprimentos, o modelo permite melhor entendimento da relação entre a maturidade do SMD e a maturidade da gestão da cadeia. Isso permite que uma melhor gestão da cadeia de suprimentos seja realizada, por meio da correta adequação dos SMDs às suas competências requeridas, de acordo com o nível de desenvolvimento no qual esta gestão se encontrar.

\section{Referências}

AMARATUNGA, D. et al. Quantitative and qualitative research in the built environment: application of "mixed" research approach. Work Study, v. 51, n. 1, p. 17-31, 2002. http://dx.doi.org/10.1108/00438020210415488

ANDERSSON, P.; ARONSSON, H.; STORHAGEN, N. G. Measuring Logistics Performance. Engineering Costs and Production Economics, v. 17, p. 253-262, 1989. http://dx.doi.org/10.1016/0167-188X(89)90074-8

ATTADIA, L. C. L.; MARTINS, R. A. Medição de desempenho como base para evolução da melhoria contínua. Revista Produção, v. 13, n. 2, p. 33-41, 2003.

AYERS, J. B.; MALMBERG, D. M. Supply Chain Systems: Are You Ready? Information Strategy: The Executive's Journal, p. 18-27, 2002. Disponível em: <http://ayersconsulting.com/download/SC \%20Systems \%20-\%20 Are\%20You\%20Ready.pdf>. Acesso em: 01 mar. 2008.

BEAMON, B. M. Measuring Supply Chain Performance. International Journal of Operations \& Production Management, v. 19, n. 3, p. 275-292, 1999. http:// dx.doi.org/10.1108/01443579910249714

BESSANT, J.; CAFFYN, S.; GALLAGHER, M. An evolutionay model of continuous improvement behavior. Technovation, v. 21, n. 2, p. 67-77, 2001. http://dx.doi. org/10.1016/S0166-4972(00)00023-7

BITITCI, U. S.; TURNER, T.; BEGEMANN, C. Dynamics of performance measurement systems. International Journal of Operations \& Production Management, v. 20, n. 6, p. 692-704, 2000. http:// dx.doi.org/10.1108/01443570010321676

BHAGWAT, R.; SHARMA, M. K. Performance measurement of supply chain management: A balanced scorecard approach. Computers \& Industrial Engineering, v. 53, p. 43-62, 2007. http://dx.doi.org/10.1016/j. cie.2007.04.001

BREWER, P. C.; SPEH, T. W. Using The Balanced Scorecard To Measure Supply Chain Performance. Journal of Business Logistics, v. 21, n. 1, p. 75-93, 2000.

BRYMAN, A. Research methods and organization studies. London: Unwin Hyman, 1989. http://dx.doi. org/10.4324/9780203359648

BRYMAN, A.; BELL, E. Business Research Methods. 2nd ed. Oxford: Oxford University Express, 2007.

CHAN, F. T. S. et al. A conceptual model of performance measurement for supply chains. Management Decision, v. 41, n. 7, p. 635-642, 2003. http://dx.doi. org/10.1108/00251740310495568 
CHRISTOPHER, M. Logistics and Supply Chain Management. 3rd ed. London: Pearson Education, 2005. DAOZHI, Z. et al. A New Supply Chain Maturity Model With 3-Dimension Perspective. In: INFORMATION TECHNOLOGY AND INOVATION CONFERENCE - ITIC, 2006, Hangzhou. Proceedings... Hangzhou: ITIC, 2006.

GEARY, S.; ZONNENBERG, J. P. What it means to be best in class. Supply Chain Management Review, v. 4, n. 3, p. 43-48, 2000.

GUNASEKARAN, A.; PATEL, C.; TIRTIROGLU, E. Performance measures and metrics in a supply chain environment. International Journal of Operations \& Production Management, v. 21, n. 1-2, p. 71-87, 2001. http://dx.doi.org/10.1108/01443570110358468

HAMMER, M. The Process Audit. Harvard Business Review, v. 85, n. 4, p. 111-123, Apr. 2007. PMid:17432158.

HARTER, D. E.; KRISHNAN, M. S.; SLAUGHTER, S. A. Effects of Process Maturity on Quality, Cycle time, and Effort in Software Product Development. Management Science, v. 46, n. 4, p. 451-466, 2000. http://dx.doi. org/10.1287/mnsc.46.4.451.12056

HOLMBERG, S. A systems perspective on supply chain measurements. International Journal of Physical Distribution \& Logistics Management, v. 30, n. 10 , p. 847-868, 2000. http://dx.doi. org/10.1108/09600030010351246

KENNERLEY, M.; NEELY, A. Measuring performance in a changing business environment. International Journal of Operations \& Production Management, v. 23, n. 2, p. 213-229, 2003. http://dx.doi. org/10.1108/01443570310458465

KWAK, Y. H.; IBBS, W. C. Project Management Process Maturity Model. Journal of Management In Engineering, v. 18, n. 3, p. 150-155, 2002. http:// dx.doi.org/10.1061/(ASCE)0742-597X(2002)18:3(150)

LAMBERT, D. M.; COOPER, M. C. Issues in Supply Chain Management. Industrial Marketing Management, v. 29, p. 65-83, 2000. http://dx.doi.org/10.1016/ S0019-8501(99)00113-3

LAMBERT, D. M.; POHLEN, T. L. Supply Chain Metrics. The International Journal of Logistics Management, v. 12, n. 1, p. 1-19, 2001. http://dx.doi. org/10.1108/09574090110806190

LOCKAMY III, A.; McCORMACK, K. The development of a supply chain management process maturity model using the concepts of business process orientation. Supply Chain Management: An International Journal, v. 9, n. 4, p. 272-278, 2004. http://dx.doi. org/10.1108/13598540410550019

MARTINS, R. A. et al. Quality Management as Trigger to Performance Measurement Systems Evolution. In: INDUSTRIAL ENGINEERING RESEARCH CONFERENCE IIE - ANNUAL CONFERENCE, 2008, Hangzhou. Proceedings... Vancouver: Industrial Engineering Research Conference, 2008.

MIGUEL, P. A. C. Estudo de caso na engenharia de produção: estruturação e recomendações para sua condução. Revista Produção, v. 17, n. 1, p. 216-229, 2007. http://dx.doi. org/10.1590/S0103-65132007000100015

MORGAN, C. Structure, speed and salience: performance measurement in the supply chain. Business Process
Management Journal, v. 10, n. 5, p. 522-536, 2004. http://dx.doi.org/10.1108/14637150410559207

NEELY, A.; GREGORY, M.; PLATTS, K. Performance measurement system design. International Journal of Operations \& Production Management, v. 15, n. 4 , p. $80-116,1995$. http://dx.doi. org/10.1108/01443579510083622

NEELY, A. Measuring Business Performance. London: The Economist Books Ltd., 1998. 208 p.

OLIVEIRA, G. T.; MARTINS, R. A. Efeitos da adoção do modelo do Prêmio Nacional da Qualidade na medição de desempenho: estudos de caso em empresas ganhadoras do prêmio. Revista Gestão e Produção, v. 15, n. 2, p. 247-259, 2008. http://dx.doi.org/10.1590/ S0104-530X2008000200004

OLIVEIRA, M. P. V. Modelo de Maturidade de Processos em Cadeias de Suprimentos: Precedências e os Pontos-Chave de Transição. 2009. Tese (Doutorado em Administração)-Universidade Federal de Minas Gerais, Belo Horizonte, 2009.

PERFORMANCE MEASUREMENT GROUP - PMG Competitive Advantage of Best in Class Supply Chains. Pennsylvania: PMG, 2007. Disponível em: <http://www.pmgbenchmarking.com/public/survey/ advantagesofbic.pdf>. Acesso em: 17 nov. 2008.

PIRES, S. R. I.; ARAVECHIA, C. H. M. Measuring Supply Chain Performance. In: ANNUAL CONFERENCE OF THE PRODUCTION AND OPERATIONS MANAGEMENT SOCIETY, 12., 2001, Orlando. Proceedings... Orlando: POMS, 2001.

PIRES, S. R. I. Gestão da Cadeia de Suprimentos: conceitos, estratégias, práticas e casos. 2. ed. São Paulo: Atlas, 2009.

SEURING, S. A. Assessing the rigor of case study research in supply chain management. Supply Chain Management: An International Journal, v. 13, n. 2, p. 128-137, 2008. http://dx.doi.org/10.1108/13598540810860967

SIMCHI-LEVI, D.; KAMINSKY, P.; SIMCHI-LEVI, E. Introduction to supply chain management. In: SIMCHILEVI, D.; KAMINSKY, P.; SIMCHI-LEVI, E. Designing and Managing the Supply Chain: concepts, strategies and case studies. 2nd ed. Boston: McGraw-Hill, 2003.

STEVENS, G. Integrating the supply chain. International Journal of Physical Distribution \& Logistics Management, v. 19, n. 8, p. 3-8, 1989. http://dx.doi. org/10.1108/EUM0000000000329

SUPPLY-CHAIN COUNCIL. Supply-Chain Operations Reference-model. version 9.0 - Overview. Supply-Chain Council, 2008. Disponível em: <http://www.supply-chain. org/resources/scor>. Acesso em: 5 nov. 2008.

TEIXEIRA, R.; LACERDA, D. P. Gestão da cadeia de suprimentos: análise dos artigos publicados em alguns periódicos acadêmicos entre os anos de 2004 e 2006. Gestão \& Produção, v. 17, n. 1, p. 207-227, 2010. http://dx.doi.org/10.1590/S0104-530X2010000100016

TEZZA, R.; BORNIA, A. C.; VEY, I. H. Sistemas de medição de desempenho: uma revisão e classificação da literatura. Gestão \& Produção, v. 17, n. 1, p. 75-93, 2010. http:// dx.doi.org/10.1590/S0104-530X2010000100007

VAN HOEK, R. I. Measuring the unmeasurable - measuring and improving performance in the supply chain. Supply Chain Management: An International 
Journal, v. 3, n. 4, p. 187-192, 1998. http://dx.doi. org/10.1108/13598549810244232

VAN AKEN, E. M. et al. Assessing maturity and effectiveness of enterprise performance measurement systems. International Journal of Productivity and Performance Management, v. 54, n. 5-6, p. 400-418, 2005. http:// dx.doi.org/10.1108/17410400510604557

VENKATRAMAN, N.; HENDERSON, J. C. Real Strategies for Virtual Organizing. Sloan Management Review, v. 40, n. 1, p. 33-48, 1998.
VOSS, C.; TSIKRIKTSIS, N.; FROHLICH, M. Case research in operations management. International Journal of Operations \& Production Management, v. 22, n. 2, p. 195-219, 2002. http://dx.doi. org/10.1108/01443570210414329

WETTSTEIN, T.; KUENG, P. A Maturity Model for Performance Measurement Systems. Management Information Systems, p. 113-122, 2002.

YIN, R. K. Estudo de Casos. 3. ed. Porto Alegre: Bookman, 2005. 
